\title{
AVALIAÇÃO DO SUBLEITO DE RODOVIAS VICINAIS DE BAIXO VOLUME DE TRÁFEGO POR MEIO DE ENSAIOS GEOTÉCNICOS ${ }^{1}$
}

\author{
Taciano Oliveira da Silva ${ }^{2}$, Carlos Alexandre Braz de Carvalho ${ }^{3}$, Dario Cardoso de Lima ${ }^{3}$, Maria Lúcia \\ Calijuri $^{3}$, Carlos Cardoso Machado ${ }^{4}$ e Tales Moreira de Oliveira ${ }^{5}$
}

\begin{abstract}
RESUMO - Este artigo aborda a viabilidade técnica do uso de solos locais, preferencialmente os de comportamento geotécnico laterítico, em camadas de reforço do subleito de rodovias vicinais de baixo volume de tráfego, através de ensaios geotécnicos e da classificação MCT (Miniatura, Compactado, Tropical). Para este propósito, consideraram-se amostras deformadas de solos coletadas no subleito das estradas VCS 493 e VCS 296, pertencente à malha rodoviária vicinal do município de Viçosa-MG, Brasil. O programa de estudo de laboratório envolveu a realização dos seguintes ensaios: (i) granulometria conjunta; (ii) limites de Atterberg (LL e LP); (iii) massa específica dos grãos do solo; (iv) compactação e CBR realizados na energia do Proctor normal; (v) compactação Mini-MCV; e (vi) perda de massa do corpo-de-prova por imersão em água. Os resultados desta pesquisa possibilitaram verificar que os solos de comportamento laterítico foram enquadrados no grupo LG' na classificação MCT e que, mesmo apresentando valores de Limite de liquidez e Índice de plasticidade elevados, quando compactados na energia do Proctor normal e, conseqüentemente, imersos em água, não apresentaram expansão com valor significativo no ensaio de CBR. Por outro lado, as areias saprolíticas apresentam perda de massa por imersão (Pi) difícil de ser previsto na Metodologia MCT, pois podem apresentar valores muito elevados e baixos, conforme a compacidade atingida durante o processo de compactação dos corpos-de-prova, como pode ser notado no resultado da amostra 8
\end{abstract}

Palavras-chave: Estradas não pavimentadas, Solos e Reforço de subleito.

\section{LOW TRAFFIC SECONDARY ROAD SUBGRADE EVALUATION BY GEOTECHNICAL TESTS}

\begin{abstract}
This paper approaches the technical feasibility of using local soils, preferably those of lateritic geotechnical behavior, in subgrade reinforcement layers of low traffic volume vicinal roads through geotechnical testing and MCT methodology (Miniature, Compacted, Tropical). Therefore, disturbed soil samples were collected from the road subgrade VCS 493 and VCS 296 from to the vicinal road net of the city of Viçosa, Minas Gerais state, Brazil. The laboratory study program included the following trials: (i) grain-size distribution; (ii) Atterberg limits (LL and PL); (iii) specific mass of soil grain; (iv) compaction and CBR carried out in normal Proctor energy; (v) mini-MCV compaction; and (vi) specimen weight loss by water immersion. By using the results from this, it was possible to check if soils presenting lateritic behavior were classified in the LG' group of the MCT methodology, and that they even presenting high values of liquid limit and plasticity index, when compacted in normal Proctor energy and therefore water immersed, they did not present expansion with a significant value in CBR trial. On the other hand, the saprolitic sands presented mass loss by water immersion (Pi) difficult to be predicted through the MCT methodology because they can present very high and low values according to compacteness reached during compaction process, as it can be noted in the result from sample 8.
\end{abstract}

Keywords: Soils, Subgrade reinforcement and Unpaved roads.

\footnotetext{
${ }^{1}$ Recebido em 21.03.2009 e aceito para publicação em 20.04.2011.

${ }^{2}$ Universidade Federal de São João Del-Rei, UFSJ, Brasil. E-mail: <taciano@ufsj.edu.br>

${ }^{3}$ Departamento de Engenharia Civil, Universidade Federal de Viçosa, UFV. E-mail: <cabraz@ufv.br>e < declima@ufv.br> e <calijuri@ufv.br>.

${ }^{4}$ Departamento de Engenharia Florestal, Universidade Federal de Viçosa, UFV. E-mail: <machado@ufv.br>.

${ }^{5}$ Graduando em Engenharia Civil pela Universidade Federal de Viçosa, UFV. E-mail: <talesciv04@yahoo.com.br>.
} 


\section{INTRODUÇÃO}

As estradas exercem importante papel no desenvolvimento econômico e social de um país. No Brasil, atualmente o transporte rodoviário é considerado a principal via de integração do país, fundamental no transporte de passageiros e no escoamento da produção industrial e agrícola brasileira (TRINDADE et al., 2005).

No estado de Minas Gerais, as rodovias municipais interligam a grande maioria dos polos agropecuários do interior do estado às rodovias estaduais e federais pavimentadas, escoando as produções agropecuárias e abastecendo os grandes centros consumidores. No entanto, de acordo com ANTT (2005), em Minas Gerais, $87,64 \%$ das rodovias municipais ainda se encontram em leito natural.

A falta de solos com características geotécnicas apropriadas, exigidas pelos órgãos rodoviários para a construção de estradas, torna-se um dos grandes entraves para o setor de transportes no Brasil, visto que volumes maiores de cargas são transportados, com maior frequência, a distâncias cada vez mais longas e problemáticas, exigindo que as estradas pavimentadas e não pavimentadas, sejam transitáveis em qualquer época do ano (MACHADO et al, 2003).

Segundo Charman (1988 apud D’ÁVILA, 1996), as estradas não pavimentadas constituem área do conhecimento em que muito pouca tecnologia formal foi desenvolvida. Praticamente, a totalidade das especificações técnicas para o revestimento primário desse tipo de estrada fundamenta-se nos ensaios tradicionais de classificação de solos: análise granulométrica e limite de Atterberg.

O baixo volume de tráfego na maioria das rodovias vicinais repercute de maneira positiva, pois condiciona uma estrutura de pavimento mais econômica. Entretanto, o método de dimensionamento tradicional utilizado no Brasil (DNIT, 2006), estabelecido na década de 1960, não se mostra uma ferramenta adequada para o dimensionamento de pavimentos flexíveis de baixo volume de tráfego, pois, ao empregar este método, incorre-se numa extrapolação das dimensões das camadas do pavimento, que pode conduzir a estruturas pouco econômicas. Além disso, na maioria das vezes, o método de dimensionamento supracitado não possibilita a utilização de materiais locais que apresentam bom comportamento mecânico, diferentemente da metodologia MCT (Miniatura, Compactado, Tropical), que pode ser empregada para a identificação e seleção de solos locais, com potencial aplicação na construção de estradas vicinais, e consequentemente para produzir reduções nos custos de pavimentação das referidas vias.

De acordo com Thuler (2005), a utilização de solos de comportamento laterítico em bases de pavimentos de baixo volume de tráfego já está consagrada em vários estados do Brasil, principalmente no estado de São Paulo, apesar desses materiais não atenderem às especificações do método de dimensionamento do DNIT. Sabe-se que a necessidade de melhor se classificar os solos tropicais levou ao desenvolvimento da metodologia MCT (Miniatura, Compactado, Tropical) por Nogami e Villibor (1995), baseados em pesquisa de laboratório e de campo realizados a partir do início da década de 70. Essa metodologia classifica os solos em grupos de comportamento laterítico e não laterítico. No Município de Viçosa-MG, várias ocorrências de solos podem apresentar comportamento laterítico sob os critérios da metodologia MCT, conforme indicado no trabalho de Azevedo (1999).

Diante desse contexto, busca-se, neste estudo, avaliar, através de ensaios geotécnicos físicos e mecânicos, a viabilidade técnica do uso de solos locais, preferencialmente de comportamento laterítico, em camadas de reforço do subleito de rodovias vicinais de baixo volume de tráfego. Para esse fim, foram selecionadas duas rodovias não pavimentadas de baixo volume de tráfego, localizadas no Município de Viçosa-MG. Essas rodovias, além de atender a pequenas comunidades e propriedades rurais, apresentam características comuns como plataforma de terraplenagem pequena (5 a 8 metros), pontos sinuosos com curvas de raio pequeno, deficiência de drenagens superficial e profunda.

\section{MATERIAL E MÉTODOS}

\section{1 Área de estudo}

O Município de Viçosa, com uma área de 300,2 km², está localizado ao norte da Zona da Mata do estado de Minas Gerais, a 229 km de Belo Horizonte, Brasil, entre as latitudes $20^{\circ} 41^{\prime} 20^{\prime \prime} \mathrm{S}$ a $20^{\circ} 49^{\prime} 35^{\prime \prime} \mathrm{S}$ e as longitudes $42^{\circ} 49^{\prime} 36^{\prime \prime} \mathrm{W}$ a $42^{\circ} 54^{\prime} 27^{\prime \prime} \mathrm{W}$, a uma altitude média de $650 \mathrm{~m}$. Limita-se ao norte com os Municípios de Teixeiras e Guaraciaba, ao sul com Paula Cândido e Coimbra, a leste com Cajuri e São Miguel do Anta, e a oeste com o Município de Porto Firme (IBGE, 2008), conforme se apresenta na Figura 1. 


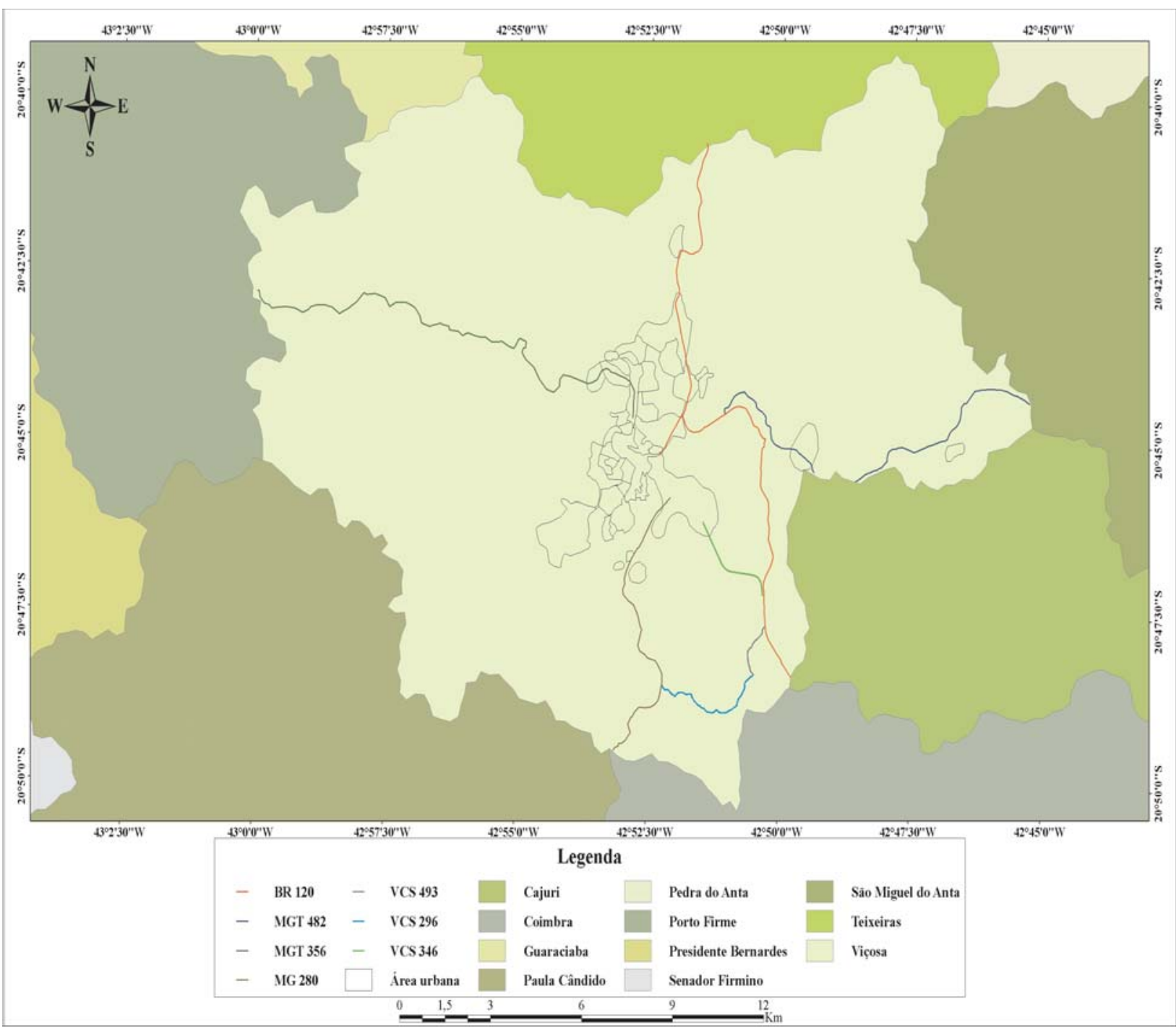

Figura 1 - Localização das estradas não pavimentadas VCS 493 e VCS 296 no município de Viçosa-MG. Figure 1 - Location of unpaved roads VCS 493 and VCS 296 in the municipality of Viçosa-MG.

\subsection{Solos}

As 14 amostras deformadas de solo utilizadas neste estudo foram coletadas no subleito das estradas vicinais não pavimentadas VCS 493 e VCS 296, localizadas na área rural do Município de Viçosa, Minas Gerais, Brasil. De cada ponto de coleta, extraíram-se aproximadamente $40 \mathrm{~kg}$ de solo, em profundidades variando de 60 a $80 \mathrm{~cm}$, a partir do leito da estrada. As amostras 1, 2, 3 e 4 foram coletadas na rodovia VCS 493, e as demais na rodovia VCS 296.

\subsection{Métodos}

Inicialmente, as amostras de solos foram secas ao ar, destorroadas, passadas na peneira \#4 (4,8 mm), acondicionadas em sacos plásticos e armazenadas, para serem empregadas nos experimentos geotécnicos descritos nos itens subsequentes.

\subsubsection{Ensaios de caracterização geotécnica}

Os experimentos realizados para caracterização geotécnica das amostras de solo foram os que seguem:

Revista Árvore, Viçosa-MG, v.35, n.4, p.825-833, 2011 
granulometria conjunta (ABNT, 1984a), limites de Atterberg (ABNT, 1984a; ABNT, 1984b), e massa específica dos grãos do solo (ABNT, 1984c).

\subsubsection{Ensaios de compactação e Índice de Suporte Califórnia (CBR)}

Os experimentos de compactação foram realizados na energia do ensaio Proctor Normal, segundo a metodologia descrita na ABNT (1986), para determinação do peso específico aparente seco máximo $\left(\gamma_{\text {dmáx }}\right)$ e da umidade ótima $\left(\mathrm{W}_{\mathrm{ot}}\right)$ dos solos em estudo. Definidos os parâmetros ótimos de compactação, determinaramse os valores dos parâmetros CBR e expansão das amostras de solo analisadas, de acordo com a metodologia proposta pelo DNER, (1994a).

\subsubsection{Classificação MCT}

As amostras de solo referenciadas anteriormente também foram identificadas segundo a Metodologia MCT. Para isso, realizaram-se os ensaios de MiniMCV e perda de massa por imersão, conforme os procedimentos prescritos no método do DNER (1994b), com necessárias consultas complementares (DNER, 1994c; 1994d; 1994e; 1994f).

\subsubsection{Ensaio de compactação Mini-MCV e moldagem dos corpos de prova}

As amostras utilizadas no ensaio de compactação Mini-MCV foram passadas na peneira \#10 (2,0 mm). Este ensaio consiste, basicamente, na compactação de corpos de prova em dimensões reduzidas (diâmetro de 50 mm) em energias variáveis, até alcançar a exsudação ou 256 golpes. É executado com energia de compactação variável e massa úmida de solo constante, obedecendo-se às seguintes etapas: (i) pesagem de, no mínimo, 5 porções de solo, cada uma com $1 \mathrm{~kg}$, e armazenamento destas em sacos plásticos, com posterior adição de água, de modo a ter umidade crescente, mantendo-se as porções fechadas em embalagens plásticas até o início do processo de compactação; (ii) pesagem de 200 g de solo para cada umidade, iniciando-se o processo de compactação pelo ponto mais úmido; (iii) aplicação de números sucessivos de golpes, medindo-se as alturas dos corpos de prova a cada 4n golpes; (iv) encerramento do processo de compactação quando a diferença de altura (An A4n) for menor que $0,1 \mathrm{~mm}$, e ocorrer exsudação ou o número de golpes totalizar 256; (v) repete-se a sequência de (i) a (iv) para outros valores de umidades.
Para cada amostra analisada, foram confeccionados cinco corpos de prova compactados dinamicamente, para diversos números de golpes, com uma variação de umidade em torno de $2 \%$ para cada corpo de prova, e esses foram compactados na ordem do mais úmido para o mais seco.

\subsubsection{Ensaio de perda de massa por imersão}

Após a compactação Mini-MCV dos corpos de prova, eles foram preparados para a obtenção da perda de massa por imersão em água. O procedimento utilizado consistiu em promover a extrusão de cerca de $10 \mathrm{~mm}$ do corpo de prova do molde metálico, colocando-se em seguida o conjunto na posição horizontal dentro de um recipiente com água, com uma cápsula para a coleta do material desprendido da porção exposta. Cada amostra foi deixada em imersão por um período de tempo em torno de $20 \mathrm{~h}$, com uma lâmina de água de, aproximadamente, $1 \mathrm{~cm}$ acima da superfície externa do molde.

\section{RESULTADOS E DISCUSSÃO}

\subsection{Ensaios de caracterização geotécnica, compactação e CBR}

Os solos são identificados e classificados comumente em Mecânica dos Solos, sobretudo nos estudos preliminares ou nas obras de pequeno vulto, mediante a determinação de propriedades físicas via experimentos de granulometria e de limites de Atterberg. A Tabela 1 apresenta as informações referentes à distribuição granulométrica (ABNT, 1995), os limites de Atterberg e índice de plasticidade, e peso específico dos grãos das 14 amostras de solos analisadas. As Tabelas 2 e 3 introduzem, respectivamente, os resultados dos ensaios de compactação e CBR das referidas amostras.

Os índices físicos, limite de liquidez (LL) e índice de plasticidade (IP) ainda são utilizados para avaliar a variação de volume dos solos compactados, bem como a variação do teor de umidade por secagem (contração) ou por imersão em água (expansão). A variação de volume excessiva, sobretudo das camadas subjacentes ou constituintes dos pavimentos, é comumente considerada indesejável para o bom comportamento mecânico dos materiais empregados em camadas de pavimentos flexíveis. Para as finalidades rodoviárias, DNIT (2006) adota um máximo de 25\% para Limite de liquidez e 6\% para o Índice de plasticidade, para materiais empregados em camadas de base estabilizadas granulometricamente. 
Tabela 1 - Resultados dos ensaios geotécnicos: granulometria, limites de Atterberg, peso específico dos grãos dos solos. Table 1 - Geotechnical testing data: grain-size distribution, Atterberg limits, specific weight of soil grains.

\begin{tabular}{|c|c|c|c|c|c|c|c|c|c|c|c|c|c|c|c|}
\hline & \multirow{2}{*}{$\begin{array}{l}\text { Propriedades } \\
\text { analisadas }\end{array}$} & \multicolumn{14}{|c|}{ Amostras de solos } \\
\hline & & 1 & 2 & 3 & 4 & 5 & 6 & 7 & 8 & 9 & 10 & 11 & 12 & 13 & 14 \\
\hline \multirow{10}{*}{ 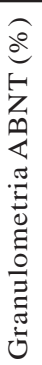 } & $\operatorname{Argila}(\phi \leq 0,002 \mathrm{~mm})$ & 73 & 41 & 50 & 67 & 31 & 50 & 61 & 28 & 51 & 72 & 44 & 38 & 47 & 74 \\
\hline & Silte $(0,002<\phi \leq 0,06 \mathrm{~mm})$ & 6 & 25 & 4 & 19 & 18 & 15 & 15 & 21 & 11 & 7 & 23 & 16 & 26 & 10 \\
\hline & Areia fina $(0,06<\phi \leq 0,2 \mathrm{~mm})$ & 8 & 10 & 14 & 4 & 18 & 14 & 4 & 20 & 17 & 6 & 12 & 19 & 5 & 3 \\
\hline & Areia média $(0,2<\phi \leq 0,6 \mathrm{~mm})$ & 12 & 23 & 31 & 9 & 29 & 20 & 17 & 28 & 20 & 14 & 20 & 23 & 16 & 11 \\
\hline & Areia grossa $(0,6<\phi \leq 2 \mathrm{~mm})$ & 1 & 1 & 1 & 1 & 4 & 1 & 3 & 3 & 1 & 1 & 1 & 4 & 6 & 2 \\
\hline & Pedregulho( $\phi>2 \mathrm{~mm})$ & 0 & 0 & 0 & 0 & 0 & 0 & 0 & 0 & 0 & 0 & 0 & 0 & 0 & 0 \\
\hline & LL (\%) & 92 & 48 & 55 & 72 & 49 & 54 & 90 & 61 & 58 & 84 & 58 & 85 & 55 & 76 \\
\hline & LP (\%) & 42 & 31 & 32 & 37 & 26 & 31 & 52 & 21 & 35 & 43 & 30 & 36 & 36 & 37 \\
\hline & IP (\%) & 50 & 17 & 23 & 35 & 23 & 23 & 38 & 40 & 23 & 41 & 28 & 49 & 19 & 39 \\
\hline & $\gamma_{\mathrm{s}}\left(\mathrm{kN} / \mathrm{m}^{3}\right)$ & 28 & 27 & 28 & 27 & 27 & 28 & 27 & 25 & 27 & 27 & 28 & 28 & 27 & 28 \\
\hline
\end{tabular}

Tabela 2 - Resultados dos ensaios de compactação.

Table 2 - Compaction test data.

\begin{tabular}{ccc}
\hline & Parâmetros do Ensaio de Compactação \\
\hline Amostras de solos & Umidade ótima $-\mathrm{w}_{\text {ot }}(\%)$ & $\begin{array}{r}\text { Peso específico aparente } \\
\text { máximo }-\gamma_{\text {dmáx }}\left(\mathrm{kN} / \mathrm{m}^{3}\right)\end{array}$ \\
\hline 1 & & 14,27 \\
2 & 31,92 & 16,37 \\
3 & 21,79 & 17,12 \\
4 & 19,37 & 14,14 \\
5 & 29,20 & 16,17 \\
6 & 21,34 & 14,05 \\
7 & 30,00 & 12,54 \\
9 & 39,09 & 14,16 \\
10 & 30,56 & 14,24 \\
11 & 28,19 & 14,32 \\
13 & 30,08 & 14,47 \\
14 & 28,00 & 15,20 \\
\end{tabular}

Tabela 3 - CBR (\%) e Expansão ${ }_{\mathrm{CBR}}$.

Table $3-C B R(\%)$ and Swelling ${ }_{C B R}$.

\begin{tabular}{ccc}
\hline Amostras de solos & CBR (\%) & Expansão $_{\mathrm{CBR}}(\%)$ \\
\hline 1 & 2,61 & 0,21 \\
2 & 3,24 & 0,42 \\
3 & 4,92 & 0,30 \\
4 & 8,16 & 0,78 \\
5 & 4,92 & 0,72 \\
6 & 8,42 & 0,23 \\
7 & 8,42 & 0,62 \\
8 & 2,61 & 0,21 \\
9 & 6,52 & 0,61 \\
10 & 3,24 & 0,51 \\
1 & 8,42 & 0,62 \\
13 & 6,52 & 0,67 \\
14 & 4,92 & 0,29 \\
\hline
\end{tabular}


No entanto, Nogami e Villibor (1995), baseados em experiências de laboratório e de campo, relataram que os referidos índices possuem aplicações limitadas para os casos de solos e condições ambientais tropicais, o que pode ser verificado, neste estudo, pelos resultados dos índices físicos e pela expansão das amostras analisadas, apresentados na Tabela 1 , em que se têm amostras de solos com LL elevados (acima de 50\%), que se expandem muito pouco, quando testados nas condições estabelecidas para a determinação dos valores de CBR de acordo com DNER (1994a). Segundo os autores supracitados, isso tem ocorrido em amostras de solos classificados pedologicamente como Latossolos e Argissolos, representativos da área de estudo desta pesquisa, conforme estudos de Azevedo (1999).

Mesmo não apresentando expansões CBR com valores significativos, é preciso ter cautela para empregar materiais como camada estrutural de pavimento, principalmente se forem camadas delgadas como um tratamento superficial. É preciso uma avaliação mais criteriosa da expansão desses materiais, tendo em vista que podem ser encontrados argilominerais expansíveis na fração fina desses solos.

Se os solos analisados não apresentarem expansões CBR com valores significativos, é recomendável uma avaliação mais criteriosa sobre a expansão desses materiais tendo em vista a possível presença de argilominerais expansíveis na fração fina, principalmente quando forem direcionados para a camada estrutural do pavimento, como camadas delgadas com tratamento superficial.

\subsection{Classificação MCT}

Na Tabela 4, encontram-se informações sobre as classificações das amostras apresentadas segundo a metodologia MCT (NOGAMI; VILLIBOR, 1995) e a classificação pedológica vigente (SANTOS et al., 2006).

A geologia do Município de Viçosa-MG é constituída por rochas referentes ao Pré-Cambriano, compreendendo gnaisses diversos e migmatitos. Ao longo dos vales e das vias fluviais, aparecem os sedimentos quaternários, constituindo depósitos aluvionares de caráter argiloso, argiloarenoso ou arenoso (IGA, 1976). Algumas das amostras de solo que foram classificadas pela metodologia MCT como pertencentes ao grupo NG' compreendem os saprolíticos argilosos. De acordo com Nogami e Villibor (1995), classificam-se nesse grupo os solos superficiais pedogenéticos não lateríticos. Alguns trechos das estradas vicinais investigadas possuem o leito bastante encaixados no terreno natural devido ao processo errôneo de conformação da plataforma por patrolamento excessivo, havendo pontos críticos que alcançaram o horizonte saprolítico, como mostra a Figura 2.

Tabela 4 - Índices classificatórios e classificações das amostras segundo a metodologia MCT e a pedologia. Table 4-Qualifying indexes and classifications of the samples according to the MCT methodology and pedology.

\begin{tabular}{|c|c|c|c|c|c|c|}
\hline \multirow{2}{*}{$\begin{array}{l}\text { Amostras de } \\
\text { solos }\end{array}$} & \multicolumn{4}{|c|}{ Índices classificatórios } & \multirow{2}{*}{ Classificação MCT } & \multirow{2}{*}{ Classificação pedológica } \\
\hline & $c^{\prime}$ & d' & $\mathrm{Pi}(\%)$ & $e^{\prime}$ & & \\
\hline 1 & 2,44 & 10,4 & 0 & 1,24 & $\mathrm{NG}^{\prime}$ & Saprolítico \\
\hline 2 & 3,11 & 22 & 82 & 1,29 & NG' & Saprolítico \\
\hline 3 & 3,22 & 42,6 & 23 & 0,89 & LG' & Saprolítico \\
\hline 4 & 4,78 & 8,04 & 0 & 1,36 & NG' & Latossolo Vermelho - Amarelo \\
\hline 5 & 4,22 & 26 & 58 & 1,11 & LG' & Saprolítico \\
\hline 6 & 4,78 & 15,1 & 0 & 1,10 & LG' & Argissolo Vermelho - Amarelo \\
\hline 7 & 3,56 & 5,8 & 0 & 1,51 & NG' & Latossolo Vermelho Amarelo \\
\hline 8 & 3,11 & 4,6 & 260 & 1,90 & NG' & Saprolítico \\
\hline 9 & 4,78 & 14 & 0 & 1,13 & NG' & Argissolo Vermelho - Amarelo \\
\hline 10 & 4,00 & 17,7 & 0 & 1,04 & LG' & Saprolítico \\
\hline 11 & 4,78 & 19,4 & 69 & 1,20 & NG' & Latossolo Vermelho - Amarelo \\
\hline 12 & 4,22 & 6,0 & 82 & 1,61 & NG' & Latossolo Vermelho - Amarelo \\
\hline 13 & 4,22 & 85 & 69 & 0,97 & LG' & Saprolítico \\
\hline 14 & 4,22 & 20,5 & 0 & 0,99 & LG' & Latossolo Vermelho - Amarelo \\
\hline
\end{tabular}

Revista Árvore, Viçosa-MG, v.35, n.4, p.825-833, 2011 

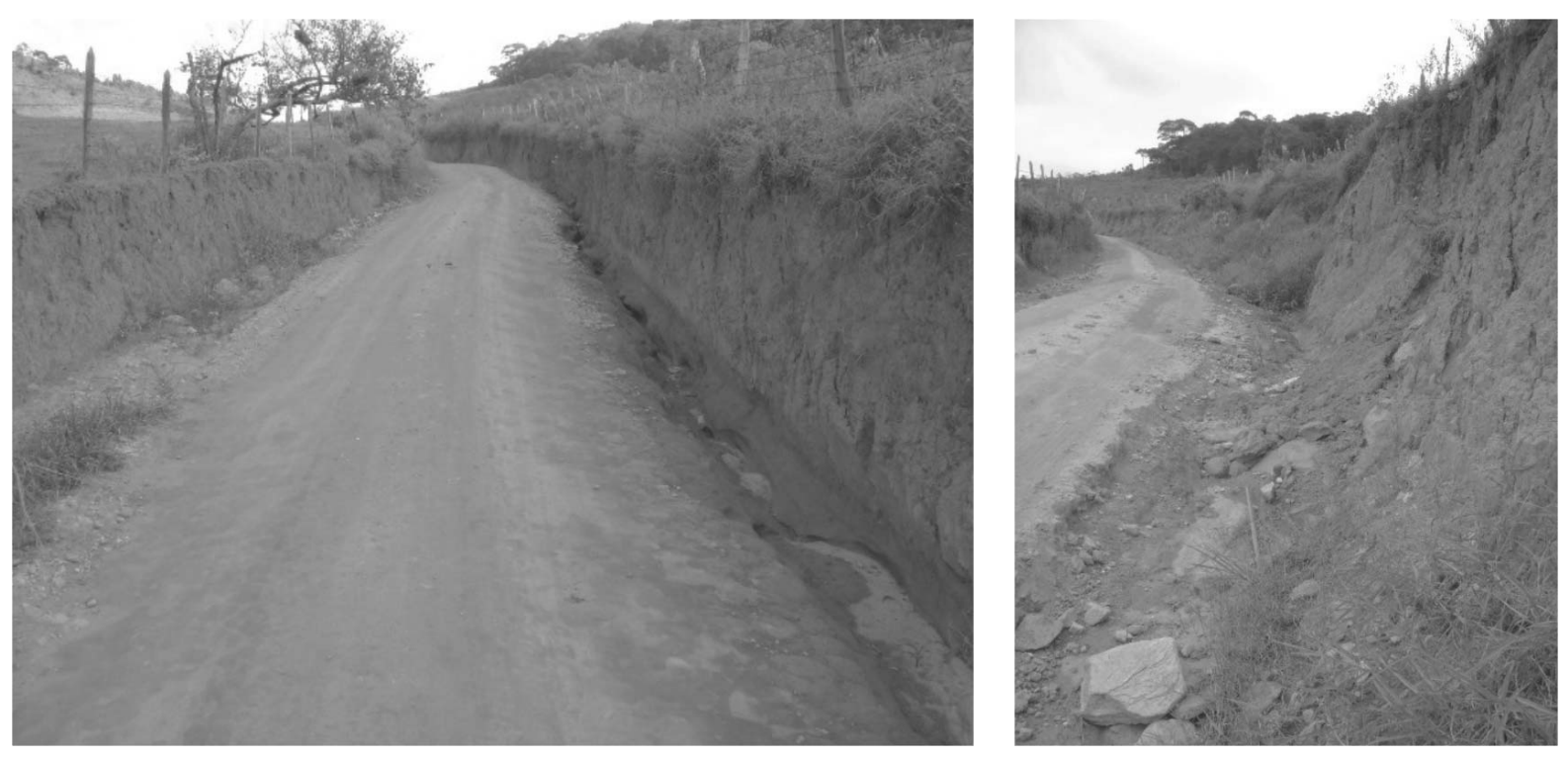

Figura 2 - Trechos da estrada vicinal VCS 296 encaixados no terreno natural.

Figure 2 - Road sections of the vicinal road VCS 296 embedded in natural ground.

As amostras de solos 1, 2, 3, 5, 8, 10 e 13 foram classificadas pedologicamente como saprolíticos possivelmente provenientes do gnaisse. Mineralogicamente, na fração areia dessas amostras foi possível constatar a presença de pseudomorfo de mineral micáceo, embora as amostras 3, 5, 10 e 13 tenham sido classificadas pela metodologia MCT como pertencentes ao grupo LG'. A presença desse mineral no solo, segundo Nogami e Villibor (1995), pode elevar o limite de liquidez, como constatado nos resultados apresentados na Tabela 1; causar a diminuição da massa específica aparente seca máxima quando compactado e elevar a umidade ótima de compactação, de acordo com o apresentado na Tabela 2, além da diminuição da capacidade de suporte, conforme valores apresentados na Tabela 3.

De acordo com Nogami e Villibor (1995), os integrantes mais frequentes do grupo LG' da classificação $\mathrm{MCT}$, do qual fazem parte algumas amostras, tais quais a 6 e a 14, têm sido as argilas e as argilas arenosas, que constituem o horizonte $\mathrm{B}$ dos solos conhecidos pedologicamente por Latossolos e Argissolos. A colapsibilidade em estado natural, por imersão em água, é uma propriedade frequentemente observada nos solos desse grupo, sobretudo quando apresentam partículas bem desenvolvidas. Nessa condição, apresentam-se altamente permeáveis, apesar de serem granulometricamente argila, de acordo com análise e relato de Azevedo (1999).

\section{CONCLUSÕES}

Para este estudo, as amostras de solo coletadas nos subleitos pertencentes ao horizonte $\mathrm{B}$, unidades pedológicas de maior ocorrência no Município de ViçosaMG, pertencentes às classes pedológicas dos Argissolos e Latossolos apresentaram condições geotécnicas favoráveis, como valores CBR e expansão CBR, para serem utilizadas em pavimentos de rodovias de baixo volume de tráfego, de acordo com a classificação MCT e ensaios geotécnicos físicos e mecânicos.

Os solos de comportamento laterítico foram enquadrados pela metodologia MCT no grupo LG'. Esses solos, mesmo possuindo elevados valores de LL e IP, quando compactados na energia do ensaio Proctor normal e, consequentemente, imersos em água, não tiveram expansão CBR com valores significativos.

Numa possível determinação de composições soloagregado, em que o principal componente é um solo de comportamento laterítico, para utilização em camadas de pavimento, para a região de Viçosa é relevante considerar sua natureza mineralógica micácea, visto

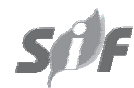

Revista Árvore, Viçosa-MG, v.35, n.4, p.825-833, 2011 
que esse mineral tem influência significativa sobre a resposta mecânica desses solos sob a ação das cargas rodoviárias, segundo Nogami e Villibor (1995).

\section{AGRADECIMENTOS}

À Fundação de Amparo à Pesquisa do Estado da Bahia (FAPESB), pela concessão da bolsa de pesquisa ao primeiro autor, e à Universidade Federal de Viçosa - UFV, através do Departamento de Engenharia Civil, pelo suporte na coleta das amostras deformadas de solos e nos ensaios geotécnicos de laboratório.

\section{REFERÊNCIAS}

\section{ASSOCIAÇÃO BRASILEIRA DE NORMAS} TÉCNICAS - ABNT. Análise granulométrica, solos, método de ensaio, NBR 7181/84. Rio de Janeiro: 1984a. 15p.

ASSOCIAÇÃO BRASILEIRA DE NORMAS TÉCNICAS - ABNT. Solo, determinação do limite de liquidez, NBR 6459/84. Rio de Janeiro: 1984b. 6p.

\section{ASSOCIAÇÃO BRASILEIRA DE NORMAS} TÉCNICAS - ABNT. Solo, determinação da massa específica aparente, NBR 6508/84. Rio de Janeiro: 1984c. 8p.

\section{ASSOCIAÇÃO BRASILEIRA DE NORMAS} TÉCNICAS - ABNT. Solo, ensaio de compactação - procedimento, NBR 7182/ 86. Rio de Janeiro: 1986.10p.

\section{ASSOCIAÇÃO BRASILEIRA DE NORMAS} TÉCNICAS - ABNT. Solo, determinação do limite de plasticidade, NBR 7180/84. Rio de Janeiro: 1984b. 3p.

\section{ASSOCIAÇÃO BRASILEIRA DE NORMAS}

TÉCNICAS - ABNT. Rochas e solos:

terminologia, NBR 6502/95. Rio de Janeiro: 1995.18p.

\section{AGÊNCIANACIONAL DE TRANSPORTES} TERRESTRES - ANTT. Anuário Estatístico dos Transportes Terrestres. Brasília: 2005.

AZEVEDO, M. A. A. Contribuição ao estudo geotécnico de solos de ViçosaMG. 1999. 169f. Dissertação (Mestrado em Engenharia Civil) - Universidade Federal de Viçosa, Viçosa, MG, 1999.

Revista Árvore, Viçosa-MG, v.35, n.4, p.825-833, 2011

Revista Árvore, Viçosa-MG, v.35, n.4, p.825-833, 2011
D’ÁVILA, A. L. M. Bases de um sistema de gerência de estradas municipais do estado do Rio Grande do Sul. 1996. $116 f$. Tese (Doutorado em Engenharia Civil) Universidade de São Paulo, São Carlos, 1996.

DEPARTAMENTO NACIONAL DE ESTRADAS DE RODAGEM - DNER. Solos determinação do índice de suporte Califórnia utilizando amostras não trabalhadas, DNER - ME 049/94. Rio de Janeiro: 1994a. 14p.

DEPARTAMENTO NACIONAL DE ESTRADAS DE RODAGEM - DNER. Classificação de solos tropicais para finalidades rodoviárias utilizando corpos-de-prova compactados em equipamento miniatura, DNER - CLA 259/94. Rio de Janeiro: 1994b. 6p.

DEPARTAMENTO NACIONAL DE ESTRADAS DE RODAGEM - DNER. Coleta de amostras deformadas de solos. DNER - PRO 003/94. Rio de Janeiro: 1994c. 4p.

DEPARTAMENTO NACIONAL DE ESTRADAS DE RODAGEM - DNER. Compactação em equipamento miniatura, solos, método de ensaio. DNER - ME 228/94. Rio de Janeiro: 1994d. 14p.

DEPARTAMENTO NACIONAL DE ESTRADAS DE RODAGEM - DNER. Solos compactados com equipamento miniatura determinação da perda de massa por imersão, solos, método de ensaio, DNER - ME 256/94. Rio de Janeiro: 1994e. 6p.

DEPARTAMENTO NACIONAL DE ESTRADAS DE RODAGEM - DNER. Solos compactados em equipamento miniatura - MiniMCV, solos, métodos de ensaio, DNER ME 258/94. Rio de Janeiro: 1994f. 14p.

DEPARTAMENTO NACIONAL DE INFRAESTRUTURA DE TRANSPORTES - DNIT. Manual de pavimentação. 3.ed. Rio de Janeiro: Instituto de Pesquisas Rodoviárias, 2006. 274p. 
INSTITUTO BRASILEIRO DE GEOGRAFIA E ESTATÍSTICA - IBGE. Informações sobre a população. Disponível em: < http://

www.ibge.gov.br $>$. 2002, acesso em 23 de maio de 2008.

INSTITUTO DE GEOCIÊNCIAS APLICADA - IGA. Mapa Geológico do Estado de Minas Gerais. Belo Horizonte: 1976. 295p.

MACHADO, C. C.; PEREIRA, R. S.; PIRES, J. M. M. Influência do tratamento térmico do resíduo sólido industrial (grits) na resistência mecânica de um latossolo para pavimentos de estradas

florestais. Revista Árvore, v. 27, n. 4, p. 543550, 2003.

NOGAMI, J. S.; VILLIBOR, D. F. Pavimentação de baixo custo com solos lateríticos. São Paulo: Villibor, 1995. 240p.
SANTOS, H. G. et al. Sistema brasileiro de classificação de solos. 2.ed. Rio de Janeiro: Embrapa Solos, 2006. 306p.

THULER, R. B. Estudo de solos do estado do Rio de Janeiro para aplicação em rodovias de baixo volume de tráfego. 2005. 125f. Dissertação (Mestrado em Engenharia Civil) - Universidade Federal do Rio de Janeiro, Rio de Janeiro, 2005.

TRINDADE, T. P. et al. Estudo da durabilidade de misturas solo-RBI grade 81 com vistas à aplicação em estradas florestais e camadas de pavimentos convencionais. Revista Árvore, v. 29, n. 4, p. 592-600, 2005. 
